\title{
Comparison of effects of low-flow and normal-flow anesthesia on cerebral oxygenation and bispectral index in morbidly obese patients undergoing laparoscopic sleeve gastrectomy: a prospective, randomized clinical trial
}

\author{
Sedat Akbas, Ahmet Selim Ozkan \\ Department of Anesthesiology and Reanimation, Inonu University Faculty of Medicine, Malatya, Turkey
}

Videosurgery Miniinv 2019; 14 (1): 19-26

DOI: https://doi.org/10.5114/wiitm.2018.77265

\begin{abstract}
Introduction: The effects of low-flow anesthesia on cerebral oxygenation in high-risk, morbidly obese patients are not well known.

Aim: In this prospective randomized study, we compared the effects of low-flow (0.75 l/min) and normal-flow $(1.5 \mathrm{l} / \mathrm{min})$ anesthesia on regional cerebral oxygen saturation $\left(\mathrm{rSO}_{2}\right)$ and the bispectral index (BIS) in morbidly obese patients undergoing laparoscopic bariatric surgery.

Material and methods: Fifty-two morbidly obese patients undergoing laparoscopic bariatric surgery (sleeve gastrectomy) were enrolled in this study. Patients were randomly allocated to two study groups: low-flow and normal-flow anesthesia groups. Heart rate, mean arterial pressure, peripheral oxygen saturation, end-tidal carbon dioxide, BIS, left and right $\mathrm{rSO}_{2}$, and duration of anesthesia and surgery were recorded.

Results: The groups were similar with respect to age, gender, height, weight, body mass index, American Society of Anesthesiology physical status, heart rate, duration of anesthesia, and procedure. Mean arterial pressure and end-tidal carbon dioxide, both before and after insufflation of carbon dioxide and after the reverse Trendelenburg position, were significantly higher in the low-flow group. BIS values and left and right $\mathrm{rSO}_{2}$ during the preoperative and intraoperative periods were similar. Although the difference in right $\mathrm{rSO}_{2}$ between the two groups after awakening from anesthesia was statistically significant, the results of both groups remained within the normal range and were not clinically meaningful.

Conclusions: Low-flow anesthesia is safe regarding hemodynamic and respiratory characteristics, depth of anesthesia, and regional cerebral oxygen saturation in morbidly obese patients undergoing laparoscopic bariatric surgery.
\end{abstract}

Key words: morbid obesity, bispectral index, bariatric/metabolic surgery, anesthesia management, low flow anesthesia, regional cerebral oximetry.

\section{Introduction}

Obesity is a chronic disease that negatively affects the quality and duration of life [1]. Severe obesity is a highly prevalent chronic disease, which leads to substantial morbidity, premature mortality, impaired quality of life, and excess healthcare expenditures [2].

Laparoscopic bariatric surgery is the most effective long-term treatment for severe obesity and obesity-related comorbidities [3]. Insufflation of the

\section{Address for correspondence}

Sedat Akbas Ass. Prof., Department of Anesthesiology and Reanimation, Inonu University, Elazig Road 15. km, 44090 Battalgazi,

Malatya Turkey, phone: +90 5058263912, fax: +90 5058263912, e-mail: drsedatakbas@gmail.com 
abdominal cavity with carbon dioxide $\left(\mathrm{CO}_{2}\right)$ is necessary for good surgical visibility and proper surgical manipulation [4]. The level of carbon dioxide is the most potent regulatory stimulus for cerebrovascular resistance $[5,6]$.

Cerebral oximetry is therefore used to estimate regional tissue oxygenation using near-infrared spectroscopy (NIRS), which is a noninvasive and continuous measurement technique used to assess the adequacy of cerebral perfusion $[7,8]$. On the other hand, BIS is the most effective method for assessing depth of anesthesia and sedation. BIS monitoring reduces the number of intraoperative wake-ups in patients [9].

Low-flow anesthesia has several potential benefits. It improves the flow dynamics of the inhaled air, increases mucociliary clearance, maintains body temperature, reduces fluid loss, results in savings of up to $75 \%$ and reduces greenhouse gas emissions and treatment costs [10-13]. However, it is necessary to examine whether the reduction of fresh gas flow affects the quality and safety of anesthesia management, especially during high-risk operations such as laparoscopic bariatric surgery.

\section{Aim}

Low-flow anesthesia has been used for years with positive results, but its effects on cerebral oxygenation are not known in high-risk morbidly obese patients who are prone to pulmonary dysfunction related to the obesity. Therefore, our prospective randomized study compared the effects of low-flow (0.75 l/min) and normal-flow (1.5 l/min) anesthesia on regional cerebral oxygen saturation $\left(\mathrm{rSO}_{2}\right)$ and the bispectral index (BIS) in morbidly obese patients undergoing laparoscopic bariatric surgery.

\section{Material and methods}

\section{Protocol}

This trial was approved by the Local Ethic Committee of Inonu University (Protocol no: 2017/113) and registered at the US National Institutes of Health (ClinicalTrials.gov) \# NCT03438734. We conducted a prospective, randomized controlled clinical trial with 52 adult morbidly obese patients who were undergoing laparoscopic bariatric surgery in the period from June 2017 to February 2018 at a university hospital. This study was prepared in accordance with the Consolidated Standards of Reporting Trials (CONSORT) guidelines [14].

\section{Study participants}

Morbidly obese patients with American Society of Anesthesiologists (ASA) scores of III-IV, who were aged 18-65 years old, and had a BMI > $40 \mathrm{~kg} / \mathrm{m}^{2}$ were included in our study. Patients were interviewed before surgery to obtain informed consent. Patients were excluded if they were pregnant or had uncontrolled diabetes mellitus, cardiovascular disease, pulmonary disease, cerebrovascular disease, or drug and alcohol addiction. Patients who refused informed consent were also excluded.

\section{Preoperative procedures}

Patients were taken to the operating room without premedication. Standard monitoring procedures were used, including heart rate (HR), noninvasive blood pressure (NIBP), electrocardiogram (ECG), peripheral oxygen saturation $\left(\mathrm{SpO}_{2}\right)$, and body temperature monitoring by esophageal probe. In addition, regional cerebral oxygen saturation $\left(\mathrm{rSO}_{2}\right)$ monitoring was conducted with all individuals using near-infrared spectroscopy (NIRS; INVOS 4100 Cerebral Oximeter, Software Version 7.2.5.0, Somanetics Corporation, Minneapolis, USA) and depth of anesthesia was monitored with the bispectral index (BIS; VISTA Monitoring System, Massachusetts, USA) monitoring. Two cerebral NIRS and BIS sensors were placed in the right and left frontal areas under the hairline and covered with tape to prevent exposure to light.

\section{General anesthesia}

A standardized general anesthesia protocol was administered in all patients by an experienced anesthesiologist. After preoxygenation $(100 \% 4 \mathrm{l} / \mathrm{min}$ $\mathrm{O}_{2}$ for $3 \mathrm{~min}$ ), propofol $(1-2 \mathrm{mg} / \mathrm{kg})$, rocuronium $(0.8 \mathrm{mg} / \mathrm{kg})$ and fentanyl $(0.1 \mu \mathrm{g} / \mathrm{kg})$ were administered during the induction of anesthesia via the intravenous (IV) route at doses calculated according to ideal body weights. End-tidal carbon dioxide $\left(\mathrm{EtCO}_{2}\right)$ was continuously monitored after intubation. Tidal volume and ventilation rate were adjusted to maintain $\mathrm{EtCO}_{2}$ partial pressure of arterial blood at 35-45 mm Hg. Rocuronium was intermittently injected according to need based on train of four (TOF; Dräger AG, Lübeck, Germany) values. Train of four 
responses were assessed by ulnar nerve stimulation and adductor muscle response. $0.1-0.2 \mu \mathrm{g} / \mathrm{kg}$ of fentanyl was titrated for analgesia, as needed, if HR and/or mean arterial pressure (MAP) increased by $20 \%$ above baseline during surgery. Anesthesia was maintained in both groups at desflurane inhalation in a $0.5 \mathrm{O}_{2}$ oxygen-air mixture. Desflurane was discontinued with the beginning of the skin sutures and the fresh gas flow was changed to $4 \mathrm{l} / \mathrm{min}$ of oxygen for both groups. In patients who did not experience complications during the surgery, sugammadex (IV, 2-4 mg/kg, Bridion, MSD, Greenville, USA) was then administrated to reverse residual muscle relaxation at the end of surgery.

\section{Randomization}

This study was planned as a randomized prospective trial. Randomization was performed with the MedCalc for Windows (medcalc.com.tr.), version 16 statistical software. Fifty-two patients were randomly allocated to two study groups: a low-flow group (group L, $n=26$ ) and a normal-flow group (group $\mathrm{N}$ $n=26)$. Patients in group $L$ received a fresh gas flow of $4 \mathrm{l} / \mathrm{min}$ for the first $10 \mathrm{~min}$ and were then maintained with a fresh gas flow of $0.75 \mathrm{l} / \mathrm{min}$. Patients in group $\mathrm{N}$ received the same initial fresh gas flow of $4 \mathrm{l} / \mathrm{min}$ for the first $10 \mathrm{~min}$ but were then maintained with a fresh gas flow of $1.5 \mathrm{l} / \mathrm{min}$. All patients were mechanically ventilated with a tidal volume of $8 \mathrm{ml} / \mathrm{kg}$ based on ideal body weight and a frequency of 12-14 breaths/min using a Dräger Primus ventilator (Dräger AG, Lübeck, Germany). Age-related minimum alveolar concentration values were determined and expressed as a percentage of volume. All patients received the standard surgical procedures determined by the same team of surgeons with experience in gastroenterology surgery. Pneumoperitoneum pressure ranged between 10 and $12 \mathrm{~mm} \mathrm{Hg}$. Also the pneumoperitoneum level was $30-45^{\circ}$. Surgical management of sleeve gastrectomy was not changed in any way.

\section{Postoperative management}

Patients were transferred to the post-anesthesia care unit (PACU) after surgery. Patients were transferred to the general surgery intensive care unit when they achieved a score of 9 or higher on the Modified Aldrete score (range: $0-12$; scores of 9 and above indicate that the patient can be discharged from the PACU) [15]. In all patients, postoperative analgesia was achieved with IV analgesic medication using appropriate doses of tramadol $(0.5-1 \mathrm{mg} / \mathrm{kg}$, IV) and paracetamol (1 g, IV) at the time of beginning skin sutures [16].

\section{Outcome measures}

$\mathrm{HR}, \mathrm{SpO}_{2}, \mathrm{EtCO}{ }_{2}, \mathrm{MAP}$, BIS values, left $\mathrm{rSO}_{2}\left(\mathrm{LrSO}_{2}\right)$ and right $\mathrm{rSO}_{2}\left(\mathrm{RrSO}_{2}\right)$ were recorded before anesthesia $\left(T_{0}\right), 10$ min after intubation $\left(T_{1}\right), 5$ min before insufflation of $\mathrm{CO}_{2}\left(T_{2}\right), 5$ min after insufflation of $\mathrm{CO}_{2}\left(T_{3}\right), 5$ min after the reverse Trendelenburg position was applied $\left(T_{4}\right), 5$ min after the supine position was applied $\left(T_{5}\right), 5$ min after desufflation of $\mathrm{CO}_{2}\left(T_{6}\right)$, and $15 \mathrm{~min}$ after awakening from anesthesia $\left(T_{7}\right)$. In addition to anesthesia and surgery times, perioperative and postoperative complications were recorded.

\section{Statistical analysis}

On the basis of Kemerci's et al. [17] study and the assumption that a difference of $10 \mathrm{U}$ on cerebral oximetry is clinically relevant, using the power calculation method (OpenEpi, Version 3), assuming an $\alpha$ of 0.05 and a $\beta$ of 0.80 , we calculated that 19 patients per group should be included in this study. Data were analyzed using the SPSS (Statistical Package for Social Sciences Statistics for Windows, Version 22.0 Software. Armonk, NY: IBM Corp). As some pre- and anesthetic characteristics of patients were distributed abnormally, nonparametric statistics was used. Quantitative data are presented as mean or standard deviation and categorical data are shown as numbers or percentages. Continuous variables were compared between the groups using the Mann-Whitney U-test. Categorical variables were summarized using frequencies and percentages (\%) and compared between the groups using the $\chi^{2}$ test. The results were evaluated at a $95 \%$ confidence interval at a significance level of $p<0.05$.

\section{Results}

The two groups were similar with respect to age, gender, height, weight, body mass index (BMI), ideal body weight (IBW), ASA physical status, fentanyl consumption and duration of pneumoperitoneum. The mean duration of anesthesia was also similar in both groups (161.15 $\pm 41.17 \mathrm{~min}$ in group $\mathrm{L}$ and 184.69 $\pm 46.41 \mathrm{~min}$ in group $\mathrm{N}$ ), as was the mean duration of surgery $(144.23 \pm 40.36 \mathrm{~min}$ in group $\mathrm{L}$ and 166.92 
\pm 42.59 min in group N). Desflurane consumption was significantly lower in group $\mathrm{L}$ than group $\mathrm{N}(p<0.001)$. Demographic and procedural data are presented in Table I.

The HRs were similar in both groups $(p>0.05$ for all time points). MAPs at $T_{2}, T_{3}$, and $T_{4}$ were sig- nificantly higher in group $L$ than group $\mathrm{N}(p=0.041$, $p=0.008$ and $p=0.019$, respectively). $\mathrm{EtCO}_{2}$ values at the same time points $\left(T_{2}, T_{3}\right.$, and $\left.T_{4}\right)$ were also significantly higher in group $L$ than group $N(p=$ $0.016, p=0.001$ and $p=0.002$, respectively). MAP and $\mathrm{EtCO}_{2}$ values between the two groups were not

Table I. Demographic and procedure data

\begin{tabular}{|c|c|c|c|c|c|}
\hline \multirow[t]{2}{*}{ Parameter } & \multicolumn{2}{|c|}{ Group L $(n=26)$} & \multicolumn{2}{|c|}{ Group N $(n=26)$} & \multirow[t]{2}{*}{$P$-value } \\
\hline & Range & Mean \pm SD & Range & Mean \pm SD & \\
\hline Age [years] & $18-64$ & $35.69 \pm 13.02$ & $19-60$ & $35.42 \pm 10.54$ & 0.935 \\
\hline Gender, male/female & $7 / 19$ & - & $6 / 20$ & - & 0.751 \\
\hline Height $[\mathrm{cm}]$ & $149-185$ & $164.42 \pm 10.31$ & $102-193$ & $163.61 \pm 16.52$ & 0.833 \\
\hline Weight [kg] & $98-180$ & $126.24 \pm 20.98$ & $102-198$ & $129.07 \pm 27.40$ & 0.678 \\
\hline $\mathrm{BMI}\left[\mathrm{kg} / \mathrm{m}^{2}\right]$ & $36-63$ & $46.60 \pm 6.46$ & $38-59$ & $45.75 \pm 5.91$ & 0.622 \\
\hline IBW & $42-79$ & $57.80 \pm 10.49$ & $44-86$ & $58.79 \pm 11.35$ & 0.746 \\
\hline ASA, III/IV & $26 / 0$ & - & $26 / 0$ & - & 0.508 \\
\hline Sleeve gastrectomy, $n$ & 26 & - & 26 & - & - \\
\hline Desflurane consumption [ml] & $23-145$ & $70.46 \pm 29.49$ & $59-202$ & $120.57 \pm 39.25$ & $<0.001^{*}$ \\
\hline Fentanyl consumption [ $\mu g]$ & $100-200$ & $127.88 \pm 30.27$ & $90-200$ & $140.96 \pm 24.16$ & 0.091 \\
\hline Duration of pneumoperitoneum [min] & $67-186$ & $117.26 \pm 36.78$ & 79-194 & $136.65 \pm 35.36$ & 0.058 \\
\hline Duration of surgery [min] & $90-230$ & $144.23 \pm 40.36$ & $100-240$ & $166.92 \pm 42.59$ & 0.054 \\
\hline Duration of anesthesia [min] & $100-255$ & $161.15 \pm 41.17$ & $110-260$ & $184.69 \pm 46.41$ & 0.059 \\
\hline
\end{tabular}

ASA - American Society of Anesthesiologists, BMI - body mass index, Group L - low flow group, Group N - normal flow group, IBW - ideal body weight, $n$ - number, $S D$ - standard deviation.

Table II. Heart rate (HR), mean arterial pressure (MAP), peripheral oxygen saturation $\left(\mathrm{SpO}_{2}\right)$, End-tidal carbon dioxide $\left(\mathrm{EtCO}_{2}\right)$ and minimum alveolar concentration (MAC) of desflurane values

\begin{tabular}{|lcccccccccc|}
\hline Time & \multicolumn{4}{c}{ Group L $(n=26)$} & \multicolumn{5}{c|}{ Group N $(n=26)$} \\
\cline { 2 - 12 } & $\begin{array}{c}\mathrm{HR} \\
{[/ \mathrm{min}]}\end{array}$ & $\begin{array}{c}\mathrm{MAP} \\
{[\mathrm{mm} \mathrm{Hg}]}\end{array}$ & $\mathrm{SpO}_{2}$ & $\mathrm{EtCO}_{2}$ & $\mathrm{MAC}$ & $\begin{array}{c}\mathrm{HR} \\
{[/ \mathrm{min}]}\end{array}$ & $\begin{array}{c}\mathrm{MAP} \\
{[\mathrm{mm} \mathrm{Hg}]}\end{array}$ & $\mathrm{SpO}_{2}$ & $\mathrm{EtCO}_{2}$ & $\mathrm{MAC}^{\prime}$ \\
\hline$T_{0}$ & 86.42 & 105.03 & 95.53 & - & - & 84.34 & 105.34 & 96.69 & - & - \\
\hline$T_{1}$ & 96.69 & 85.46 & 98.50 & 36.19 & 0.94 & 90.61 & 82.80 & 97.92 & 34.07 & 1.39 \\
\hline$T_{2}$ & 84.30 & $80.61^{*}$ & 97.88 & $33.38^{*}$ & 0.97 & 82.80 & $72.03^{*}$ & 98.03 & $30.65^{*}$ & 1.02 \\
\hline$T_{3}$ & 86.76 & $95.23^{*}$ & 97.23 & $37.23^{*}$ & 1.01 & 85.65 & $82.73^{*}$ & 97.61 & $32.65^{*}$ & 1.02 \\
\hline$T_{4}$ & 85.84 & $85.69^{*}$ & 97.84 & $36.73^{*}$ & 0.99 & 85.53 & $73.50^{*}$ & 96.96 & $33.30^{*}$ & 1.05 \\
\hline$T_{5}$ & 84.61 & 85.19 & 97.96 & 36.69 & 0.93 & 85.69 & 87.34 & 97.80 & 37.65 & 1.00 \\
\hline$T_{6}$ & 89.50 & 88.57 & 98.19 & 37.23 & 0.90 & 85.30 & 89.34 & 98.11 & 36.96 & 0.94 \\
\hline$T_{7}$ & 99.96 & 108.80 & 94.69 & - & - & 94.80 & 106.15 & 95.42 & - & - \\
\hline
\end{tabular}

Group L - low flow group, Group $\mathrm{N}$ - normal flow group. $T_{0}$ - before anesthesia, $T_{1}-10$ min after intubation, $T_{2}-5$ min before insufflation of $\mathrm{CO}_{2}, T_{3}-5 \mathrm{~min}$ after insufflation of $\mathrm{CO}_{2}, T_{4}-5$ min after reverse Trendelenburg position, $T_{5}-5$ min after supine position, $T_{6}-5$ min after desufflation of $\mathrm{CO}_{2}$, $T_{7}-15$ min after awakening from anesthesia. *When compared with each one $(p<0.05)$. 


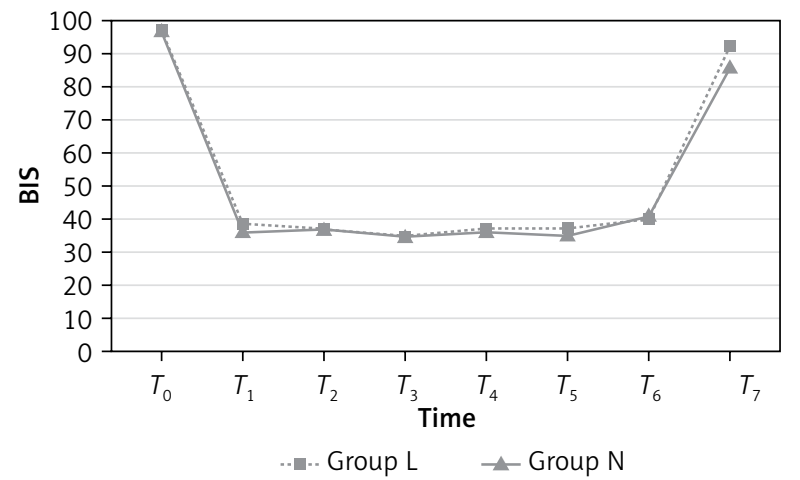

Figure 1. Bispectral index (BIS) values

significantly different at other time points. $\mathrm{SpO}_{2}$ and MAC values were similar in both groups $(p>0.05$ for all time points). $\mathrm{HR}, \mathrm{MAP}, \mathrm{SpO}_{2}, \mathrm{EtCO}_{2}$ and $\mathrm{MAC}$ data are presented in Table II.

The BIS values, representing sedation level, were similar in both groups during the preoperative $\left(T_{0}\right)$ and intraoperative $\left(T_{1}, T_{2}, T_{3}, T_{4}, T_{5}\right.$ and $\left.T_{6}\right)$ periods $(p>0.05$; Figure 1$)$; however, the BIS values at $T_{7}$ were significantly higher in group $L$ than group $N$ $(p=0.001)$. BIS values are presented in Table III.

$\mathrm{LrSO}_{2}$ measurements were similar in both groups ( $p>0.05$; Figure 2 ) at all time points. However, $\mathrm{RrSO}_{2}$ measurements at $T_{7}$ were significantly higher in group $\mathrm{N}$ than group $\mathrm{L}(p=0.018$; Figure 3$)$. Mean values (\%) for $\mathrm{rSO}_{2}$ are presented in Table IV.

\section{Discussion}

We did not observe significant differences between low-flow and normal-flow groups with respect to $\mathrm{HR}$ and $\mathrm{SpO}_{2}$. Similarly, Kupisiak et al. reported no significant differences between patients

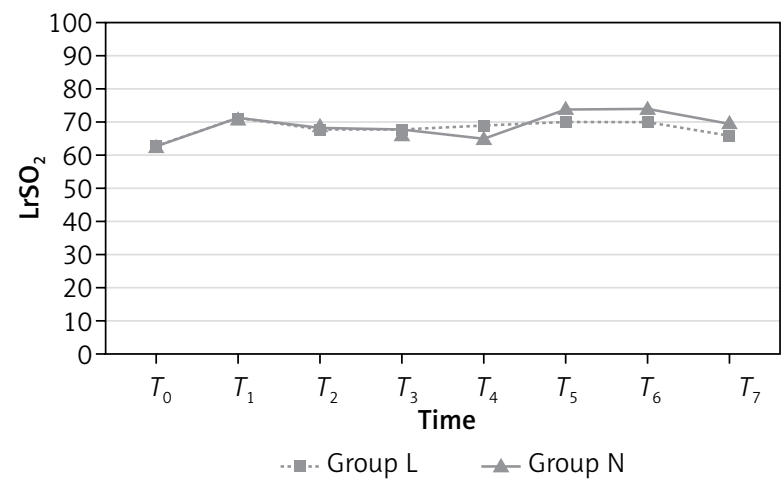

Figure 2. Left regional cerebral oxygen saturation $\left(\mathrm{LrSO}_{2}\right)$
Table III. Bispectral index (BIS) values

\begin{tabular}{|lccc|}
\hline Time & Group L $(n=26)$ & Group N $(n=26)$ & $P$-value \\
\hline$T_{0}$ & 97.61 & 97.30 & 0.513 \\
\hline$T_{1}$ & 39.73 & 36.57 & 0.167 \\
\hline$T_{2}$ & 37.92 & 37.11 & 0.690 \\
\hline$T_{3}$ & 35.73 & 35.96 & 0.889 \\
\hline$T_{4}$ & 37.61 & 36.38 & 0.556 \\
\hline$T_{5}$ & 37.61 & 35.19 & 0.257 \\
\hline$T_{6}$ & 40.61 & 41.15 & 0.873 \\
\hline$T_{7}$ & $92.50^{*}$ & $86.65^{*}$ & $0.001^{*}$ \\
\hline
\end{tabular}

Group $L$ - low flow group, Group $N$ - normal flow group. $T_{0}$ - before anesthesia, $T_{1}-10 \mathrm{~min}$ after intubation, $T_{2}-5 \mathrm{~min}$ before insufflation of $\mathrm{CO}_{2}$, $T_{3}-5$ min after insufflation of $\mathrm{CO}_{2}, T_{4}-5 \mathrm{~min}$ after reverse Trendelenburg position, $T_{5}-5 \mathrm{~min}$ after supine position, $T_{6}-5 \mathrm{~min}$ after desufflation of $\mathrm{CO}_{2}, \mathrm{~T}_{7}-15 \mathrm{~min}$ after awakening from anesthesia. *When compared with each one $(p<0.05)$.

who received low-flow and high-flow anesthesia during laparoscopic cholecystectomy with respect to $\mathrm{HR}, \mathrm{MAP}, \mathrm{EtCO}_{2}$, and $\mathrm{SpO}_{2}$; patients also did not have a high risk of awakening from anesthesia [9]. Although we found that the MAPs of the low-flow group were significantly higher than the normal-flow group at $T_{2}, T_{3}$, and $T_{4}$, the higher MAPs were considered clinically negligible because the MAPs did not increase by $20 \%$ above baseline during surgery. These results are similar to those obtained by Kupisiak et al. [9], even though patients in our study underwent a higher-risk surgical procedure and were morbidly obese.

Fassoulaki et al. reported that BIS was equally effective for depth of anesthesia with sevoflurane and desflurane [18]. In our study, anesthesia was maintained by desflurane because it has a shorter recov-

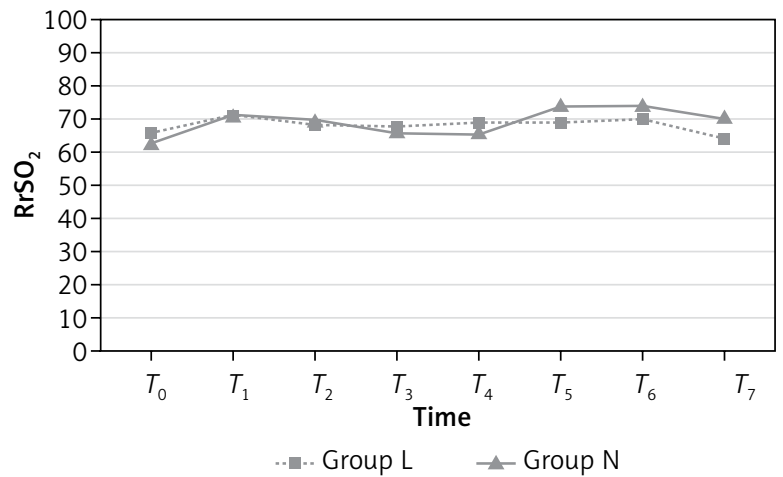

Figure 3. Right regional cerebral oxygen saturation $\left(\mathrm{RrSO}_{2}\right)$ 
Table IV. Mean values of regional cerebral oxygen saturation (\%) for left and right cerebral hemisphere

\begin{tabular}{|lcccccc|}
\hline Time & $\begin{array}{c}\text { Group L } \\
\text { Left }\end{array}$ & $\begin{array}{c}\text { Group N } \\
\text { Left }\end{array}$ & $P$-value & $\begin{array}{c}\text { Group L } \\
\text { Right }\end{array}$ & $\begin{array}{c}\text { Group N } \\
\text { Right }\end{array}$ & $P$-value \\
\hline$T_{0}$ & 63.76 & 63.34 & 0.854 & 66.15 & 62.38 & 0.117 \\
\hline$T_{1}$ & 71.92 & 71.96 & 0.988 & 71.00 & 71.23 & 0.943 \\
\hline$T_{2}$ & 68.84 & 69.15 & 0.918 & 69.26 & 70.00 & 0.813 \\
\hline$T_{3}$ & 68.19 & 66.69 & 0.629 & 68.00 & 66.96 & 0.730 \\
\hline$T_{4}$ & 69.00 & 65.61 & 0.292 & 69.73 & 66.03 & 0.235 \\
\hline$T_{5}$ & 70.30 & 74.57 & 0.208 & 69.65 & 74.65 & 0.107 \\
\hline$T_{6}$ & 70.30 & 74.15 & 0.254 & 70.80 & 74.46 & 0.201 \\
\hline$T_{7}$ & 66.46 & 70.46 & 0.169 & $64.69^{*}$ & $71.65^{*}$ & $0.018^{\star}$ \\
\hline
\end{tabular}

Group L - low flow group, Group N - normal flow group. $T_{0}-$ before anesthesia, $T_{1}-10$ min after intubation, $T_{2}-5$ min before insufflation of $\mathrm{CO}_{2}, T_{3}-5 \mathrm{~min}$ after insufflation of $\mathrm{CO}_{2}, T_{4}-5$ min after reverse Trendelenburg position, $T_{5}-5$ min after supine position, $T_{6}-5$ min after desufflation of $\mathrm{CO}_{2}, T_{7}-15$ min after awakening from anesthesia. *When compared with each one $(p<0.05)$.

ery time. We observed that BIS values in both groups were similar at all time points during the intraoperative period. Although BIS values at $T_{7}$ were significantly higher in the low-flow group (mean BIS value at $T_{7}$ : 92.50) than the normal-flow group (mean BIS value at $\left.T_{7}: 86.65\right)$, these results were considered clinically negligible because there were no anesthesia complications during the postoperative period, based on intensive care unit records.

All patients in our study met the threshold criteria for morbid obesity with a BMI of 40 or more. The mean duration of anesthesia (nearly 160 min) was longer than those. Despite this, patients in our study experienced no cerebrovascular events during the postoperative period, according to intensive care unit records.

Identification and prevention of risk factors for reductions in cerebral oxygenation are crucial tasks for all anesthetists [19]. Keeping regional cerebral saturation at safe levels during surgery may reduce perioperative complications and shorten the length of stay in the hospital [20]. We did not observe any reduction of the cerebral oxygenation compared to the baseline. Although the fresh gas flow rate was different, we provided oxygenation using the appropriate oxygen concentration.

Higher BMI scores are associated with reduced functional residual capacity and oxygenation index, increasing respiratory system resistance and workload. A BMI score over $40 \mathrm{~kg} / \mathrm{m}^{2}$ becomes an important predictor for lung volumes, respiratory mechanics, and oxygenation in patients undergoing general anesthesia [21].
Laparoscopic bariatric surgery has many benefits compared to conventional open surgery, such as less postoperative pain, shorter hospital stays, and faster recovery times [22]. However, changes in body position are required in laparoscopic bariatric surgery which can cause significant hemodynamic and respiratory changes that can reduce brain perfusion and oxygenation [23]. Specifically, laparoscopic bariatric surgery requires that patients be placed in a reverse Trendelenburg position with long-duration pneumoperitoneum for good surgical visibility and proper surgical manipulation. In addition, insufflation of the abdominal cavity with $\mathrm{CO}_{2}$ during laparoscopy results in increased intraabdominal pressure, hypercapnia, and systemic vascular resistance, and decreased functional residual capacity and pulmonary compliance. Similarly, elevated thoracoabdominal pressure disturbs cerebral venous drainage, and $\mathrm{CO}_{2}$ absorption dilates the cerebral vessels and increases cerebral blood volume. This can lead to significant changes in cerebral homeostasis, which in turn can lead to cognitive dysfunction [24, 25]. Gipson et al. found significant decreases in cerebral oxygenation associated with neurocognitive changes after 10-12 mm Hg pneumoperitoneum [26]. It is therefore crucially important to monitor cerebral oxygenation levels during laparoscopic bariatric surgery. However, it can be difficult to predict cerebral hypoxia when patients are in the Trendelenburg position required by laparoscopic bariatric surgery, due to the reduced intracranial pressure and cerebral blood flow [4]. 
Yi Jo et al. also reported that cerebral oxygen and $\mathrm{EtCO}_{2}$ values were significantly increased after pneumoperitoneum during laparoscopic bariatric surgery, but that there was no change of cerebral oxygen saturation in any of their patients [27]. In our study, we observed that no significant changes in cerebral oxygen saturations during the entire intraoperative $\left(T_{1}, T_{2}, T_{3}, T_{4}, T_{5}\right.$ and $\left.T_{6}\right)$ period. Although there was a statistically significant difference between the low-flow and normal flow groups for $\mathrm{RrSO}_{2}$ at $T_{7}$ (64.69 and 71.65, respectively), this difference was considered clinically unimportant, and neither group had a clinically superior outcome in terms of cerebral oxygenation.

Our study did not include the use of transcranial colored Doppler and jugular bulb oxygen saturation, which can help monitor cerebral function. We also did not include cognitive function assessments during the postoperative period, which could give more reliable results. Further research should make use of these measures of cerebral functioning.

\section{Conclusions}

Our study examined the effects of low-flow vs normal-flow anesthesia on hemodynamic and respiratory characteristics, depth of anesthesia, and cerebral oxygen saturation in morbidly obese patients during laparoscopic bariatric surgery. No significant perioperative or postoperative complications were recorded among our sample. While a few differences between the two groups reached statistical significance, all results were within normal ranges and none of the differences suggested any meaningful clinical differences. We therefore conclude that lowflow anesthesia can be used safely with morbidly obese patients during laparoscopic bariatric surgery.

\section{Conflict of interest}

The authors declare no conflict of interest.

\section{References}

1. Turkey Endocrinology and Metabolism Society of Obesity Diagnosis and Treatment Guide. Obesity, Dyslipidemia, Hypertension Working Group 2014; 1: 11-5.

2. Arterburn DE, Courcoulas AP. Bariatric surgery for obesity and metabolic conditions in adults. BMJ 2014; 349: g3961.

3. Kostecka M, Bojanowska M. Problems in bariatric patient care - challenges for dieticians. Videosurgery Miniinv 2017; 12: 207-15.
4. Gerges FJ, Kanazi GE, Jabbour-Khoury SI. Anesthesia for laparoscopy: a review. J Clin Anesth 2006; 18: 67-78.

5. Settakis G, Páll D, Molnár C, et al. Cerebrovascular reactivity in hypertensive and healthy adolescents: TCD with vasodilatory challenge. J Neuroimaging 2003; 13: 106-12.

6. Fülesdi B, Limburg M, Bereczki D, et al. Cerebrovascular reactivity and reserve capacity in type II diabetes mellitus. J Diabetes Complications 1999; 13: 191-9.

7. Végh T. Cerebral oximetry in general anaesthesia. Turk J Anaesthesiol Reanim 2016; 44: 247-9.

8. Jöbsis FF. Noninvasive, infrared monitoring of cerebral and myocardial oxygen sufficiency and circulatory parameters. Science 1977; 198: 1264-7.

9. Kupisiak J, Goch R, Polenceusz W, et al. Bispectral index and cerebral oximetry in low-flow and high-flow rate anaesthesia during laparoscopic cholecystectomy - a randomized controlled trial. Videosurgery Miniinv 2011; 6: 226-30.

10. Baum J. Low Flow Anaesthesia: The Theory and Practice of Low Flow, Minimal Flow and Closed System Anaesthesia. $2^{\text {nd }}$ ed. Butterworth-Heinemann; Oxford, Boston 2001.

11. Hönemann C, Hagemann O, Doll D. Inhalational anaesthesia with low fresh gas flow. Indian J Anaesth 2013; 57: 345-50.

12. Aldrete JA, Cubillos P, Sherrill D. Humidity and temperature changes during low flow and closed system anaesthesia. Acta Anaesthesiol Scand 1981; 25: 312-4.

13. Suttner S, Boldt J. Low-flow anaesthesia. Does it have potential pharmacoeconomic consequences? Pharmacoeconomics 2000; 17: 585-90.

14. Schulz KF, Altman DG, Moher D. CONSORT 2010 statement: updated guidelines for reporting parallel group randomised trials. Int J Surg 2011; 9: 672-77.

15. Aldrete JA, Kroulik D. A postanesthetic recovery score. Anesth Analg 1970; 49: 924-34.

16. Frank AHR, Groene P, von Ehrlich-Treuenstätt V, et al. Evaluation of pain relief sufficiency using the Cumulative Analgesic Consumption Score (CACS) and its modification (MACS). Videosurgery Miniinv 2017; 12: 448-54.

17. Kemerci PU, Demir A, Aydınlı B, et al. $10 \mathrm{~cm} \mathrm{H}_{2} \mathrm{O}$ PEEP application in laparoscopic surgery and cerebral oxygenation: a comparative study with INVOS and FORESIGHT. Surg Endosc 2016; 30: 971-8.

18. Fassoulaki A, Kaliontzi H, Petropoulos G, Tsaroucha A. The effect of desflurane and sevoflurane on cerebral oximetry under steady-state conditions. Anesth Analg 2006; 102: 1830-5.

19. Razlevice I, Rugyte DC, Strumylaite L, Macas A. Assessment of risk factors for cerebral oxygen desaturation during neonatal and infant general anesthesia: an observational, prospective study. BMC Anesthesiol 2016; 16: 107.

20. Casati A, Fanelli G, Pietropaoli P, et al. Monitoring cerebral oxygen saturation in elderly patients undergoing general abdominal surgery: a prospective cohort study. Eur J Anaesthesiol 2007; 24: 59-65.

21. Pelosi P, Croci M, Ravagnan I, et al. The effects of body mass on lung volumes, respiratory mechanics, and gas exchange during general anesthesia. Anesth Analg 1998; 87: 654-60.

22. Jędrzejewski E, Liszka M, Maciejewski M, et al. Age is not associated with increased surgical complications in patients after 
laparoscopic sleeve gastrectomy. Videosurgery Miniinv 2018; 13: 82-7.

23. Sprung J, Whalley DG, Falcone T, et al. The impact of morbid obesity, pneumoperitoneum, and posture on respiratory system mechanics and oxygenation during laparoscopy. Anesth Analg 2002; 94: 1345-50.

24. Cooke SJ, Paterson-Brown S. Association between laparoscopic abdominal surgery and postoperative symptoms of raised intracranial pressure. Surg Endosc 2001; 15: 723-5.

25. de Waal EE, de Vries JW, Kruitwagen CL, Kalkman CJ. The effects of low-pressure carbon dioxide pneumoperitoneum on cerebral oxygenation and cerebral blood volume in children. Anesth Analg 2002; 94: 500-5.

26. Gipson CL, Johnson GA, Fisher R, et al. Changes in cerebral ox imetry during peritoneal insufflation for laparoscopic procedures. J Minim Access Surg 2006; 2: 67-72.

27. Jo YY, Kim JY, Lee MG, et al. Changes in cerebral oxygen saturation and early postoperative cognitive function after laparoscopic gastrectomy: a comparison with conventional open surgery. Korean J Anesthesiol 2016; 69: 44-50.

Received: 15.04.2018, accepted: 3.06.2018. 